\title{
In-situ Tailor-made Additives for Molecular Crystals: A Simple Route to Morphological Crystal Engineering
}

Seung-Heon Lee, ${ }^{\dagger}$ Gyeong-Hui Lee, ${ }^{\dagger}$ Kang-Hyun Lee, ${ }^{\dagger}$ Mojca Jazbinsek, ${ }^{`}$ Bong Joo Kang, ${ }^{\S}$ Fabian Rotermund, ${ }^{\S}$ O-Pil Kwon ${ }^{*}$,

${ }^{\dagger}$ Department of Molecular Science and Technology, Ajou University, Suwon 443-749, Korea "Institute of Computational Physics, Zurich University of Applied Sciences (ZHAW), 8401

Winterthur, Switzerland

${ }^{\S}$ Department of Physics \& Department of Energy Systems Research, Ajou University, Suwon 443-749, Korea 


\section{Crystal growth with in-situ tailor-made additive DDP}

Single $\mathrm{OH} 1$ crystals are grown by slow evaporation with $\mathrm{OH} 1$ methanol solutions in the absence and presence of in-situ tailor-made additive DDP with various concentration. OH1/DDP solutions with different molar ratio of DDP $(\mathrm{OH} 1: \mathrm{DDP}=100: 0,99: 1,97: 3,95: 5,93: 7$, 90 : $10 \mathrm{~mol} / \mathrm{mol}$ (i.e., $0,1,3,5,7$ and $10 \mathrm{~mol} \%$ of DDP)) are used.

For small-scale growth experiments (total amount of methanol $=10 \mathrm{~mL}$ ), six OH1 solutions prepared by dissolving $\mathrm{OH} 1$ powder $\left(0.1 \mathrm{~g}, 3.44 \times 10^{-4} \mathrm{~mol}\right)$ in a different amount of methanol $(10.00,9.86,9.58,9.30,9.02$, and $8.60 \mathrm{~mL})$ are mixed with the corresponding amount $(0,0.14$, $0.42,0.70,0.98$, and $1.40 \mathrm{~mL})$ of $\mathrm{NaOH}$ solution $\left(2.50 \times 10^{-2} \mathrm{M}\right.$ in methanol). When an $\mathrm{OH} 1 /$ methanol solution is mixed with a $\mathrm{NaOH} /$ methanol solution, the color of the resulting solution immediately changes from orange to dark purple by the very fast acid-base neutralization reaction between the acidic $-\mathrm{OH}$ phenolic group on $\mathrm{OH} 1$ and the $\mathrm{OH}^{-}$group from $\mathrm{NaOH}$ (see also the absorption spectrum in Figure 3). Note that in these solutions, the molar ratio of $\mathrm{OH} 1: \mathrm{NaOH}=1: 0,1: 0.01,1: 0.03,1: 0.05,1: 0.07$, and $1: 0.10 \mathrm{~mol} / \mathrm{mol}$ is practically identical to $\mathrm{OH} 1: \mathrm{DDP}=100: 0,99: 1,97: 3,95: 5,93: 7,90: 10 \mathrm{~mol} / \mathrm{mol}$ (i.e., 0, 1, 3, 5, 7 and $10 \mathrm{~mol} \%$ of DDP). Notes that $\mathrm{pH}$ values of these solutions in the presence of DDP additives (i.e., by adding $\mathrm{NaOH}$ ) are close to neutral, slightly basic condition: $\mathrm{pH}=7.4,7.8,8.1,8.2$ and 8.4 for solutions with 1, 3, 5, 7 and $10 \mathrm{~mol} \%$ of DDP, respectively. The mixed solutions are kept in an oven at a constant temperature of $30{ }^{\circ} \mathrm{C}$ for solvent evaporation during few days. During this time, $\mathrm{OH} 1$ crystals spontaneously nucleate and grow. The resulting $\mathrm{OH} 1$ crystals are obtained by filtering of the remaining solution. 
In large-scale growth experiments (total amount of methanol $=100 \mathrm{~mL}$ ), we use identical experimental conditions (i.e., identical concentration, molar ratio and growth temperature) with 10 times larger amounts of $\mathrm{OH} 1$ and $\mathrm{NaOH}$.

As-grown $\mathrm{OH} 1$ crystals in the absence of additives (small-scale growth experiments) are shown in Figure 1b. In Figure 1c, the top two OH1 crystals and the bottom two OH1 crystals are grown in the presence of DDP (3 mol\%) in small- and large-scale growth experiments, respectively. Figure S1 in SI shows photographs of as-grown $\mathrm{OH} 1$ crystals in the presence of DDP in small-scale growth experiments, excepting the last $\mathrm{OH} 1$ crystal on the right in Figure $\mathrm{S} 1 \mathrm{~b}$, which is grown in a large-scale growth experiment.

\section{Crystal growth with conventional tailor-made additive DDM}

Single OH1 crystals were grown by slow evaporation with $\mathrm{OH} 1$ methanol solutions in the presence of conventional tailor-made additive DDM (OH1 : DDM = $97: 3 \mathrm{~mol} / \mathrm{mol}$ (i.e., $3 \mathrm{~mol} \%$ of DDP). OH1 $\left(0.1 \mathrm{~g}, 3.44 \times 10^{-4} \mathrm{~mol}\right)$ and $\mathrm{DDM}\left(0.0033 \mathrm{~g}, 1.03 \times 10^{-5} \mathrm{~mol}\right)$ powders are dissolved in methanol $(15 \mathrm{~mL})$. The mixed solutions were kept in an oven at a constant temperature of 30 ${ }^{\circ} \mathrm{C}$ for few days for evaporating the solvent. $\mathrm{OH} 1$ crystals spontaneously nucleate and the grown OH1 crystals are obtained by filtration. The resulting OH1 crystals are shown in Figure 1d and Figure S2 in SI.

\section{UV-vis absorption and fluorescence measurements}

To measure absorption and fluorescence spectra, $\mathrm{OH} 1$ solutions are prepared with various molar ratios of $\mathrm{OH} 1: \mathrm{NaOH}(\mathrm{OH} 1: \mathrm{DDP})$ and $\mathrm{OH} 1$ : DDM (see Figure 3). Compared to conventional chromophore concentration used for absorption and fluorescence spectroscopy $\left(10^{-}\right.$ 
${ }^{4} \sim 10^{-5} \mathrm{M}$ ), the chromophore concentration in crystal growth conditions is much higher, about 2-3 orders of magnitude higher. In order to measure the absorption and fluorescence spectra of solutions with a similar concentration as in crystal growth conditions, the initial concentration of $\mathrm{OH} 1$ in methanol of $10^{-2} \mathrm{M}$ is chosen, which is in the same order of magnitude as the OH1 solubility in methanol ${ }^{\mathrm{R} 1}$ (e.g., $17 \%$ of $\mathrm{OH} 1$ solubility in methanol at $25{ }^{\circ} \mathrm{C}\left(5.9 \times 10^{-2} \mathrm{M}\right)$ ). Different $\mathrm{OH} 1$ solutions are prepared with various amounts of additives: $\mathrm{OH} 1: \mathrm{NaOH}$ and $\mathrm{OH} 1: \mathrm{DDM}=1: 0.01,1: 0.03,1: 0.06,1: 0.10,1: 0.30,1: 0.50,1: 0.80$ and $1.00: 1.00$ $\mathrm{mol} / \mathrm{mol}$ (i.e., $0,1,3,6,10,30,50,80$, and $100 \mathrm{~mol} \%$ of DDP and $0,1,3,6,9,23,33,44,50$ and $100 \mathrm{~mol} \%$ of DDM). Absorption and fluorescence spectra are measured by using a cell of two slide glasses with a small gap and a $1 \mathrm{~mm}$ quartz cell, respectively. For comparison, pure OH1 and DDM solutions are also measured. The results are shown in Figure 3.

\section{${ }^{1}$ H NMR Measurements}

For ${ }^{1} \mathrm{H}$ NMR spectra measurements as shown in Figure 4, the initial $\mathrm{OH} 1$ concentration of $4.7 \times 10^{-2} \mathrm{M}$ in $\mathrm{CD}_{3} \mathrm{OD}$ solutions is used, which is about $80 \%$ of the saturated concentration at 25 ${ }^{\circ} \mathrm{C}$; the $\mathrm{OH} 1$ solubility in methanol at $25{ }^{\circ} \mathrm{C}$ is $5.9 \times 10^{-2} \mathrm{M}^{\mathrm{R} 1}$ All ${ }^{1} \mathrm{H}$ NMR spectra are measured by Varian $400 \mathrm{MHz} . \mathrm{CD}_{3} \mathrm{OD}(100 \%$, 99.96 atom \%D, Aldrich) and $\mathrm{NaOD}$ (40 wt \%, 99.5 atom $\% \mathrm{D}$, Aldrich) were used. After adding $\mathrm{NaOD}(40 \mathrm{wt} \%$ ) aqueous solution with various molar ratios, ${ }^{1} \mathrm{H}$ NMR spectra are measured and the results are shown in Figure 4.

In order to investigate the influence of excess $\mathrm{NaOD}$ and water on intermolecular interactions in solutions, ${ }^{1} \mathrm{H}$ NMR spectra are also measured after adding excess amounts of $\mathrm{NaOD}$ and water; these results are shown in Figure S6 and S7 in SI, respectively. By adding 
excess amounts of $\mathrm{NaOD}$ and water, no significant shift of the peaks in ${ }^{1} \mathrm{H} \mathrm{NMR}$ spectra is observed. 
(a) DDP $1 \mathrm{~mol} \%$

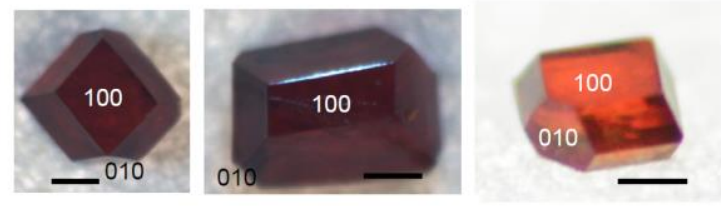

(b) DDP 3 mol\%

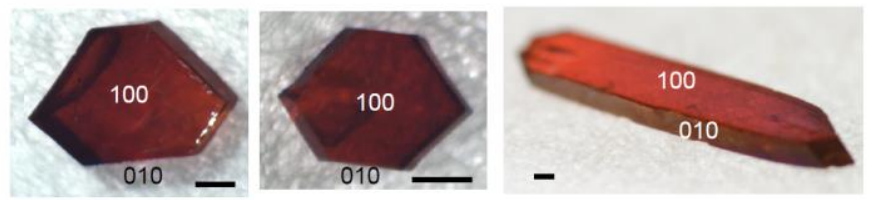

(c) DDP $5 \mathrm{~mol} \%$

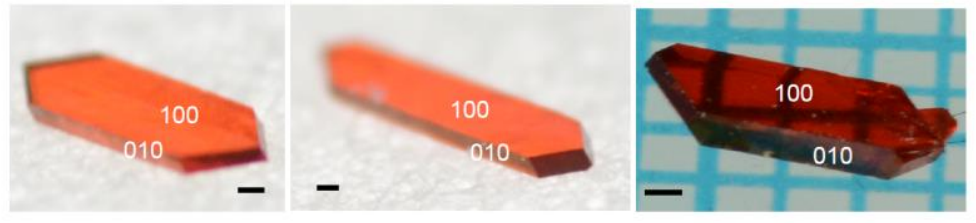

(d) DDP $7 \mathrm{~mol} \%$

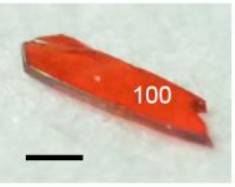

(e) DDP $10 \mathrm{~mol} \%$

100

Figure S1. Photographs of as-grown OH1 crystals in the presence of in-situ tailor-made additive DDP with a different molar ratio (scale bar: $0.5 \mathrm{~mm}$ ). In the presence of DDP additives with up to $5 \mathrm{~mol} \%$ (a-c), the as-grown $\mathrm{OH} 1$ crystals exhibit well-developed regular facets with clearly defined $b$-planes $((010)$ and (0-10) planes) with flat surfaces due to parallel-stereoselective inhibitions on the $b$-planes. However, in the presence of DDP additives of over $7 \mathrm{~mol} \%$, the asgrown $\mathrm{OH} 1$ crystals start to exhibit a slightly irregular morphology (d-e), which may be due to non-selective inhibition by the existence of relatively many DDP molecules around the growing OH1 crystal. 

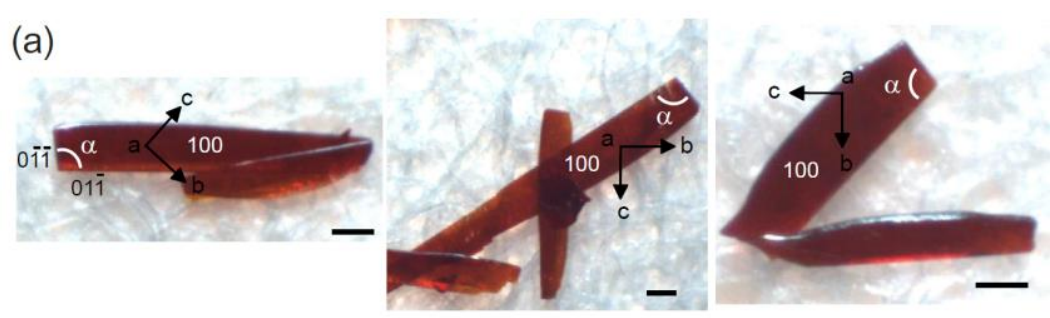

(b)

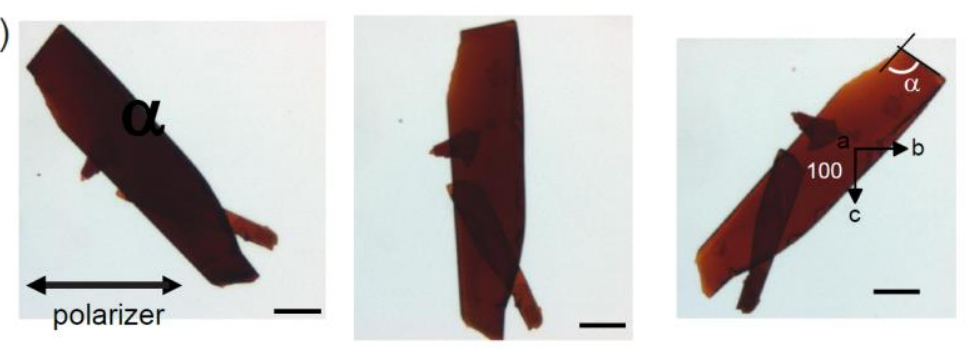

(c)

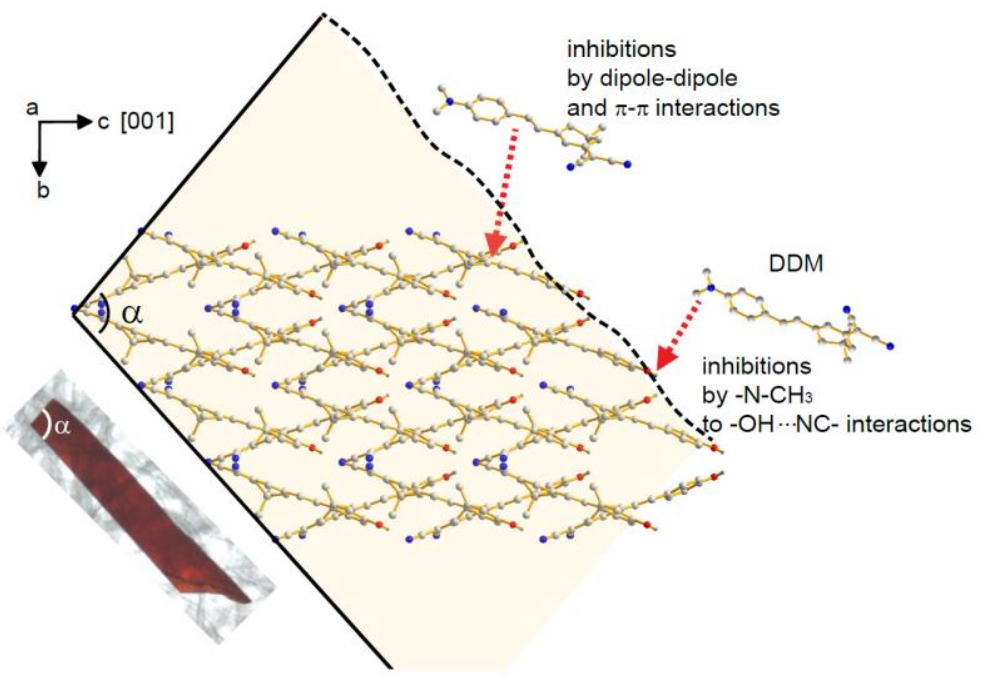

(d)

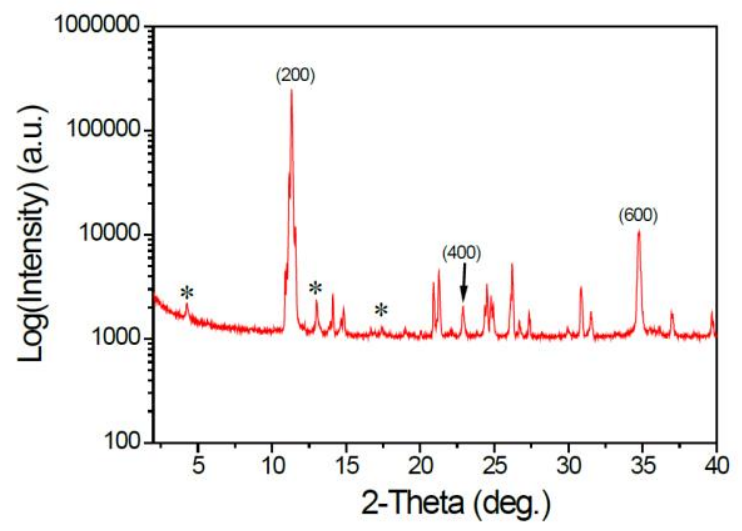

Figure S2. As-grown OH1 crystals in the presence of a conventional tailor-made additive DDM (3 mol\%). (a) Photographs of $\mathrm{OH} 1$ crystals (scale bar: $0.1 \mathrm{~mm}$ ) and (b) photographs of $\mathrm{OH} 1$ crystals on a plastic polarizer (scale bar: $0.1 \mathrm{~mm}$ ). (c) Schematic illustration of rather non- 
selective inhibitions by DDM additive on OH1 crystals. The inhibition by dipole-dipole and $\pi-\pi$ interactions between $\mathrm{OH} 1$ molecules and the additives exhibit antiparallel dipole-dipole attachment, which is called here 'antiparallel-stereoselective inhibition'. (d) Powder X-ray diffraction patterns of $\mathrm{OH} 1$ crystals grown in the presence of DDM additives. The asterisks present the diffraction peaks from a small amount of tiny pure DDM crystals.

Figure S2c illustrates the rather non-selective inhibitions by DDM additive on OH1 crystals. The tendency of antiparallel dipole-dipole aggregations and $\pi$ - $\pi$ stacking interactions between DDM additive molecules and OH1 crystal faces are very similar with that of DDP additive molecules (see Figure S5 in SI). However, the weak hydrogen bond donor (i.e., hydrogen atoms on $-\mathrm{N}-\left(\mathrm{CH}_{3}\right)_{2}$ groups) with a relatively large size on the DDM additive may create weak and complicated hydrogen bonds with $-\mathrm{OH}$ groups of $\mathrm{OH} 1$ crystals, which results in rough growth surfaces and edges (presented by the dotted line in Figure S2c).

Figure S2d shows powder X-ray diffraction patterns of $\mathrm{OH} 1$ crystals grown in the presence of DDM additives and the peaks are determined by comparison with theoretical X-ray diffraction patterns from crystal structure of $\mathrm{OH} 1$ and DDM crystals, obtained from Ref. R2 and R3, respectively. OH1 crystals grown in the presence of DDM additive exhibit identical crystal structure to $\mathrm{OH} 1$ crystals grown in the absence of additives, which is confirmed by powder X-ray diffraction patterns, in which very small diffraction peaks from pure DDM crystals are observed - note that the solubility of DDM crystals in methanol is relatively low compared to $\mathrm{OH} 1$ and the amount of DDM used in the initial solution is also much lower. 
(a)
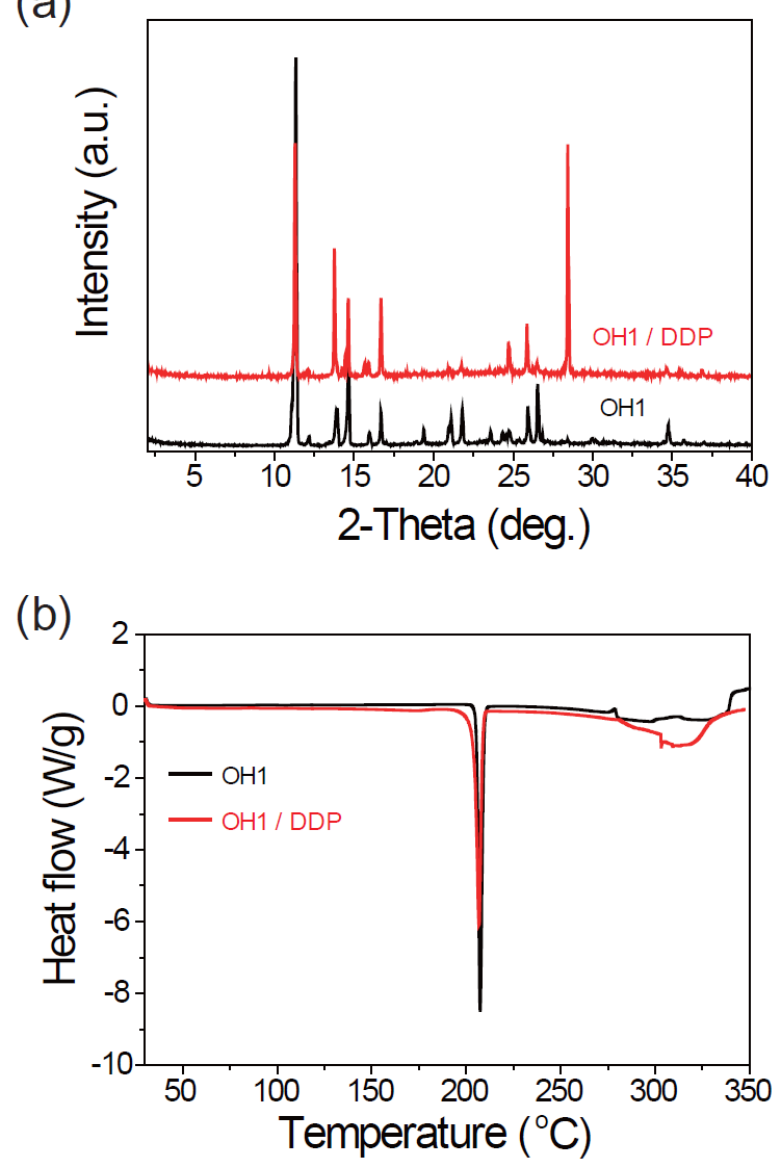

Figure S3. (a) Powder X-ray diffraction patterns and (b) differential scanning calorimetry (DSC) thermodiagrams of $\mathrm{OH} 1$ crystals grown in the absence and the presence of in-situ tailor-made additive DDP (3 mol\%). 


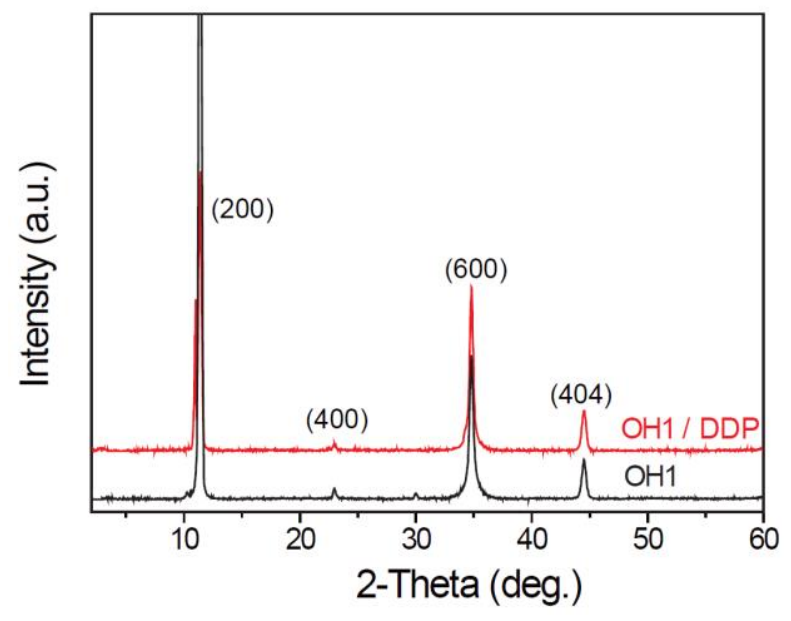

Figure S4. X-ray diffraction patterns obtained by X-ray reflection from (100) planes of $\mathrm{OH} 1$ crystals grown without additives (black curve) and grown in the presence of in-situ tailor-made additive DDP (3 mol\%, red curve). 


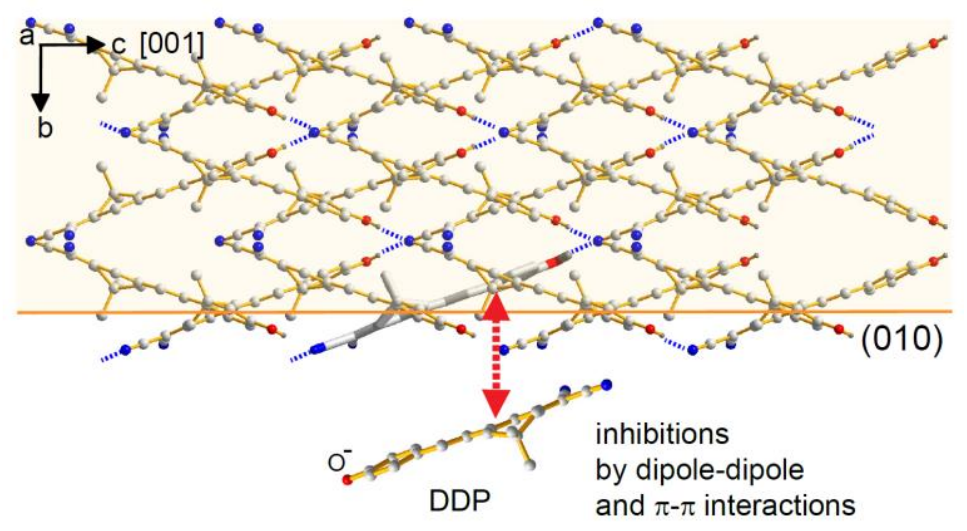

Figure S5. Schematic illustration of antiparallel-stereoselective inhibitions by DDP additives due to antiparallel dipole-dipole aggregation and $\pi-\pi$ stacking interactions on the (010) $b$-plane of $\mathrm{OH} 1$ crystals. 


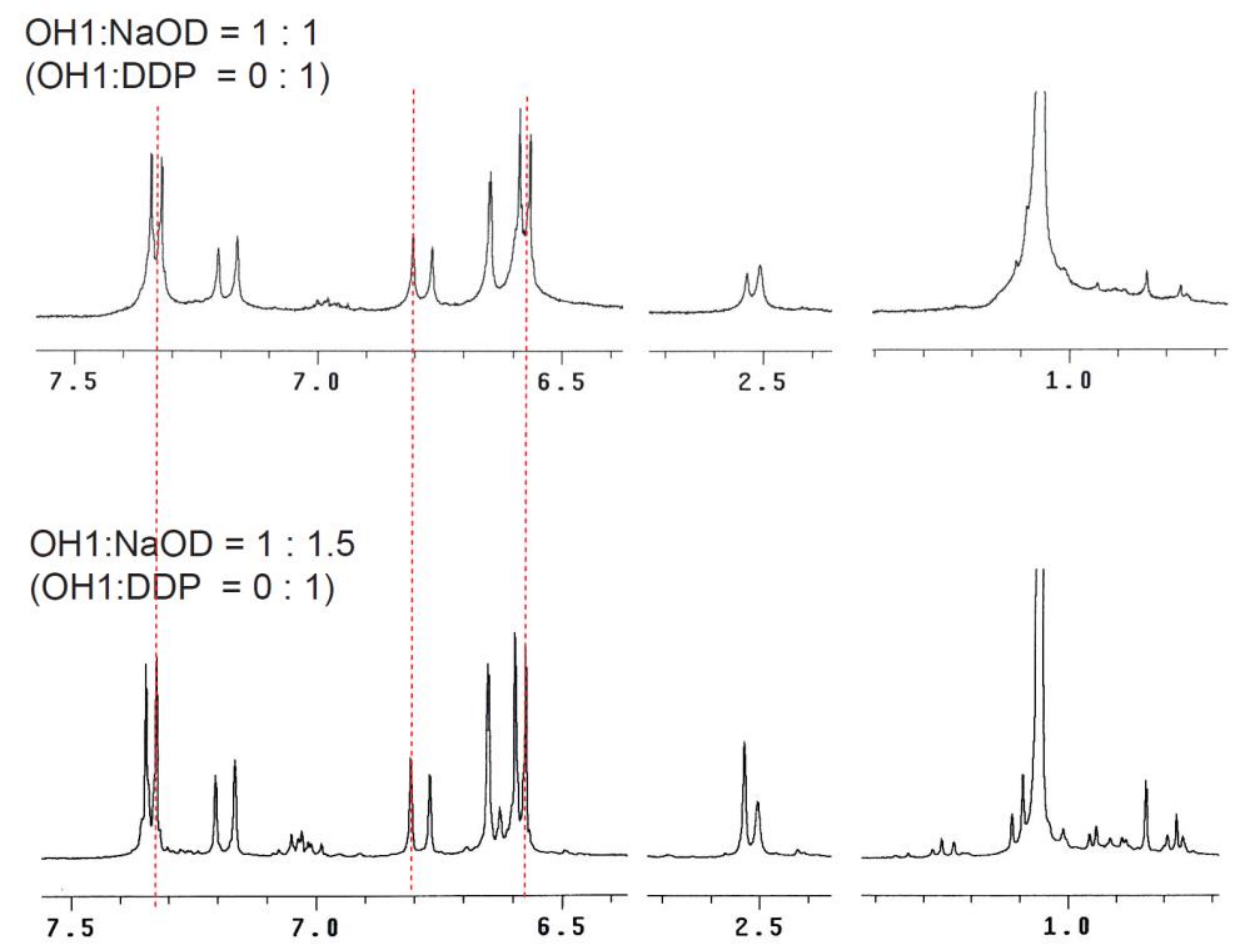

Figure S6. Influence of excess $\mathrm{NaOH}$ on ${ }^{1} \mathrm{H}$ NMR spectra of OH1: ${ }^{1} \mathrm{H}$ NMR spectra of OH1 with a different molar ratio of $\mathrm{NaOD}$ in $\mathrm{CD}_{3} \mathrm{OD}$ solution: from top to bottom, $\mathrm{OH} 1 \mathrm{NaOD}$ $(\mathrm{OH} 1: \mathrm{DDP})=1: 1(0: 1)$ and 1:1.5 (0:1). No influence of excess $\mathrm{NaOH}$ on ${ }^{1} \mathrm{H}$ NMR spectrum of $\mathrm{OH} 1$ is observed. 

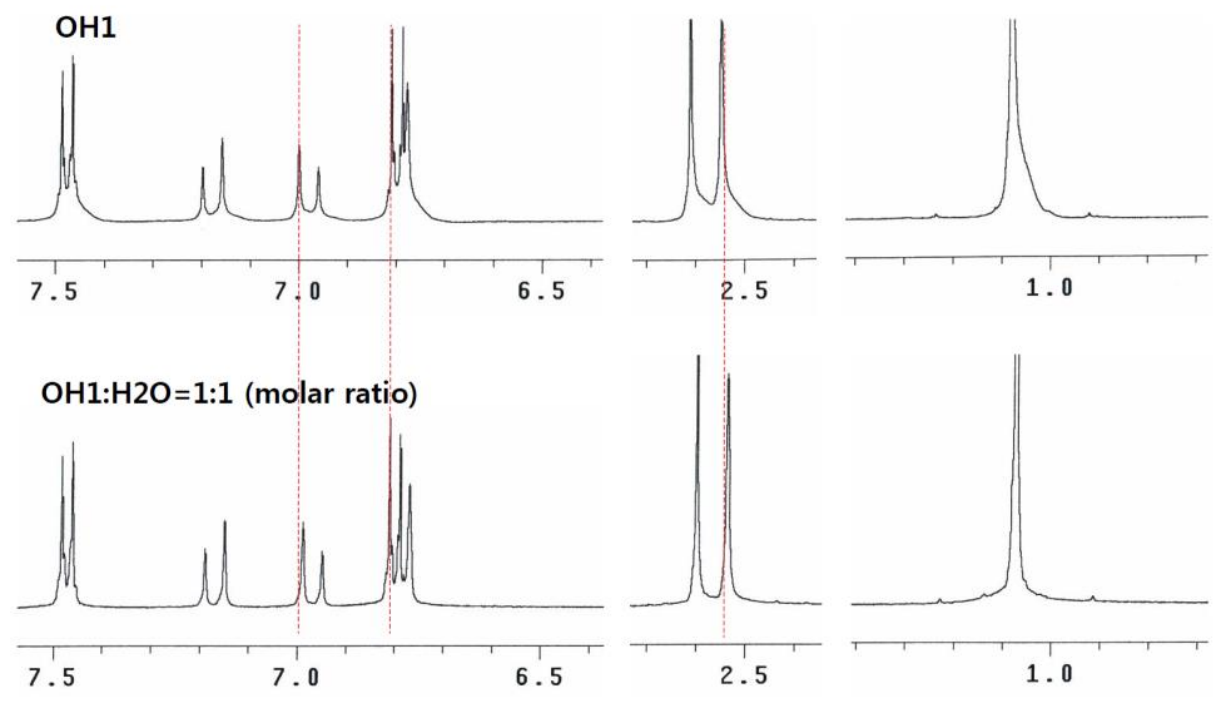

Figure S7. ${ }^{1} \mathrm{H}$ NMR spectra of $\mathrm{OH} 1$ and $\mathrm{OH} 1: \mathrm{H}_{2} \mathrm{O}(1: 1 \mathrm{~mol} / \mathrm{mol})$ in $\mathrm{CD}_{3} \mathrm{OD}$ solution. No influence of $\mathrm{H}_{2} \mathrm{O}$ molecules on ${ }^{1} \mathrm{H}$ NMR spectrum of $\mathrm{OH} 1$ is observed. 

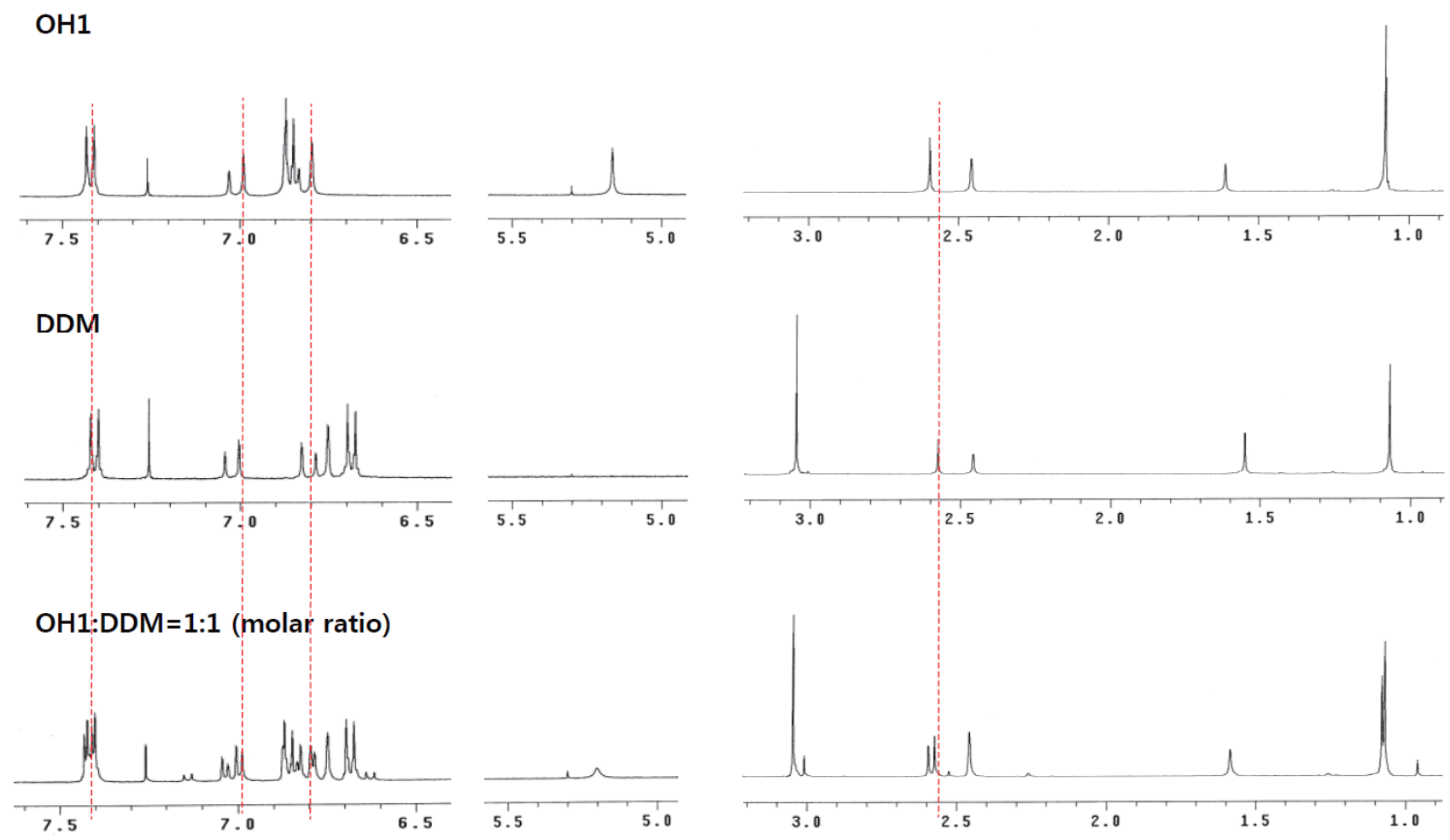

Figure S8. ${ }^{1} \mathrm{H}$ NMR spectra of $\mathrm{OH} 1, \mathrm{DDM}$ and $\mathrm{OH} 1: \mathrm{DDM}(1: 1 \mathrm{~mol} / \mathrm{mol})$ in $\mathrm{CDCl}_{3}$ solution. Due to weak interactions between $\mathrm{OH} 1$ and DDM molecules, ${ }^{1} \mathrm{H}$ NMR spectrum of OH1:DDM $(1: 1 \mathrm{~mol} / \mathrm{mol})$ exhibits no shift of the peak related to the $\pi$-conjugated bridge and is instead a simple mixture of single OH1 and DDM spectra. 
(a)

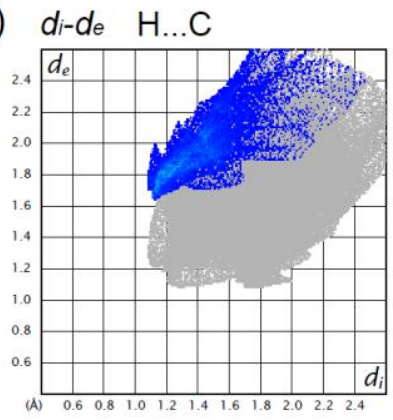

(b) $d_{i}-d_{e} \quad H . . . N$

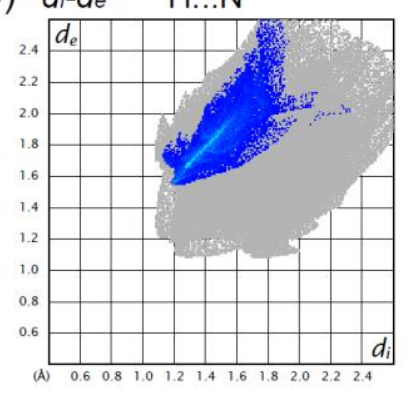

(c)

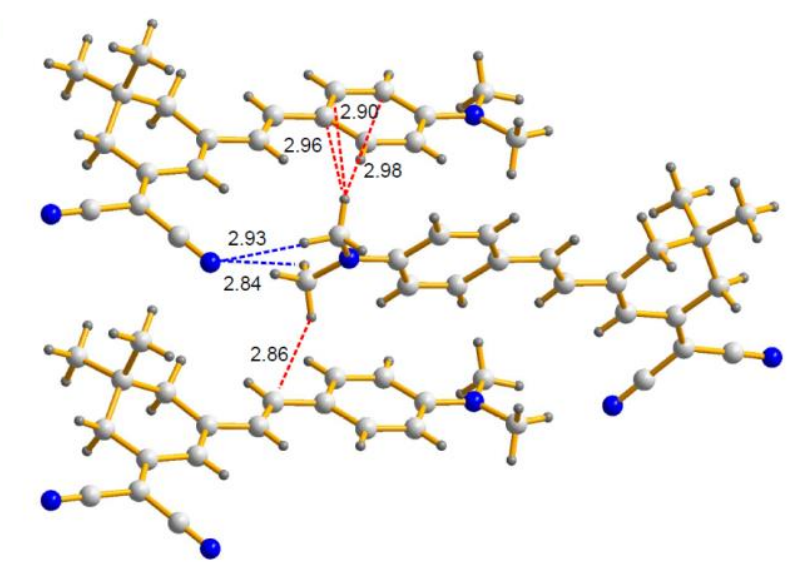

Figure S9. Hirshfeld surface analysis ${ }^{\text {R4-R6 }}$ of DDM crystals, for which the crystal structure of DDM is obtained from Ref. R3: Hirshfeld fingerprint of DDM resolved into (a) H...C and (b) $\mathrm{H} \cdots \mathrm{N}$ contacts. (c) Intermolecular interactions of two methyl groups on $-\mathrm{N}\left(\mathrm{CH}_{3}\right)_{2}$ with interatomic distance of less than $3 \AA$ are $\mathrm{H} \cdots \mathrm{C}(\pi)$ and $\mathrm{H} \cdots \mathrm{NC}$ - interactions. Note that the two methyl groups on $-\mathrm{N}\left(\mathrm{CH}_{3}\right)_{2}$ of DDM are obviously involved in supramolecular interactions in DDM crystals. 
(a)

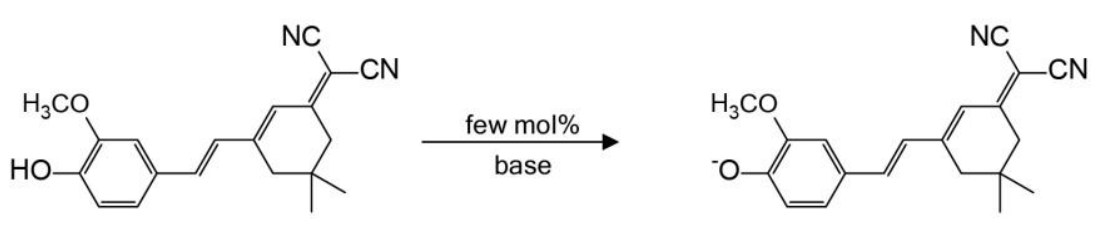

HM1

DMP (in-situ tailor-made additive)

(b)
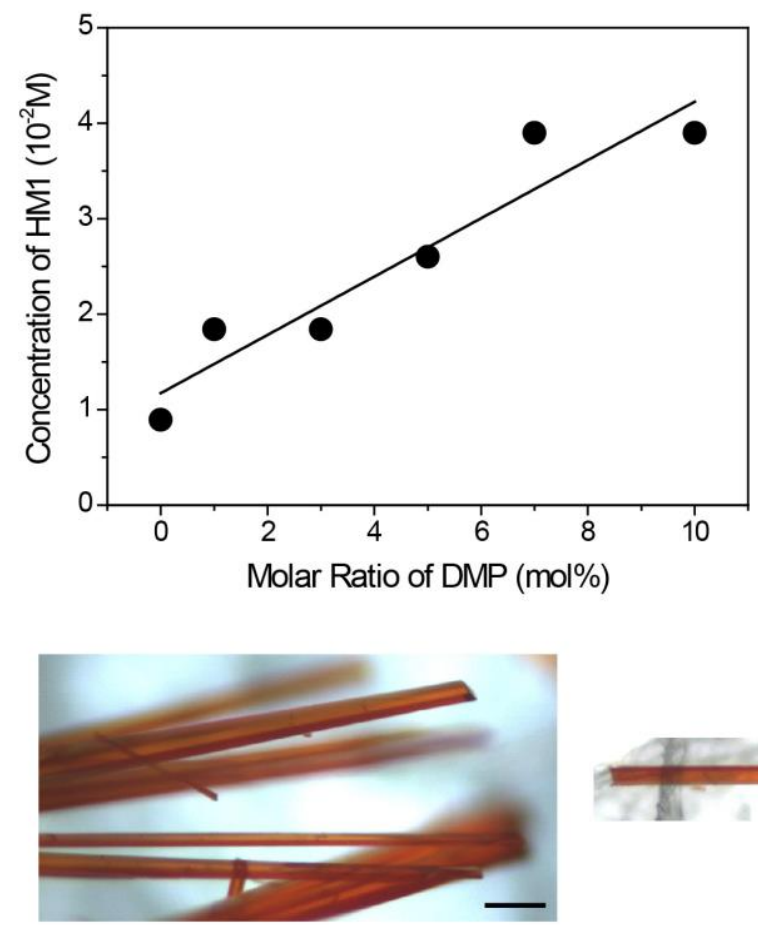

DMP $0 \mathrm{~mol} \%$

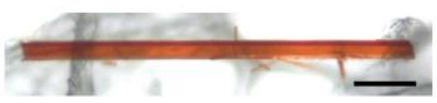

DMP $7 \mathrm{~mol} \%$

Figure S10. (a) Chemical structure of phenolic substrate molecule HM1 (2-(3-(4-hydroxy-3methoxystyryl)-5,5-dimethylcyclohex-2-enylidene)malononitrile) and in-situ tailor-made additive form DMP (4-(2-(3-(dicyanomethylene)-5,5-dimethylcyclohex-1-enyl)vinyl)-2methoxyphenolate). (b) Nucleation point measurements and selected photographs of HM1 crystals grown by slow evaporation method in methanol solution at a constant temperature of 30 ${ }^{\circ} \mathrm{C}$ with various molar ratios of DMP (scale bar: $50 \mu \mathrm{m}$ ). The solutions with molar ratio of HM1 : $\mathrm{DMP}=100: 0,99: 1,97: 3,95: 5,93: 7,90: 10 \mathrm{~mol} / \mathrm{mol}$ (i.e., 0, 1, 3, 5, 7 and $10 \mathrm{~mol} \%$ of DMP) is prepared by adding $\mathrm{NaOH}$ (i.e., $\mathrm{OH} 1: \mathrm{NaOH}=1: 0,1: 0.01,1: 0.03,1: 0.05,1: 0.07$, 
and $1: 0.10 \mathrm{~mol} / \mathrm{mol})$. The initial concentration of HM1 in methanol solution $(40 \mathrm{~mL})$ is $7.8 \times 10^{-}$ ${ }^{3} \mathrm{M}$. When $5 \mathrm{~mL}$ of the solution remains by solvent evaporation, the resulting HM1 crystals are obtained by filtering of the remaining solution. Both HM1 crystals grown in the absence and the presence of DMP additives exhibit similar morphologies with needle shape. However, with increasing concentration of DMP additives, the concentration of HM1 solution at nucleation point remarkably increases and the size (i.e. length and width of needle) of HM1 crystals decreases. The solid line presents a linear fit function to the data. 


\section{THz Generation Experiments}

For comparing the THz-wave generation characteristics using different faces of the rectangular rod-shaped $\mathrm{OH} 1$ crystals, THz waves are generated by optical rectification of 1600nm pump pulses with pulse duration of 150 fs. The temporal time traces of the generated $\mathrm{THz}$ waves are recorded by electro-optic sampling technique using $800 \mathrm{~nm}$ probe pulses and a 1-mmthick $<110>$ ZnTe electro-optic crystal in dry air at room temperature in a similar setup reported in Ref. R7.

The generated $\mathrm{THz}$ spectral shape is affected by the phonon modes of the generation and detection crystals. The spectral center of mass $f_{\mathrm{c}}$ and the bandwidth of the generated $\mathrm{THz}$ wave are determined as follows: as shown in Figure S11 in SI, the spectral center of mass $f_{\mathrm{c}}$ of the generated $\mathrm{THz}$ wave is defined as the $\mathrm{THz}$ frequency at which the normalized integral $\mathrm{THz}$ amplitude reaches 0.5 and the bandwidth of $\mathrm{THz}$ spectra is defined as the difference of the $\mathrm{THz}$ frequencies whose normalized integral $\mathrm{THz}$ amplitude equals 0.75 and 0.25 , respectively.

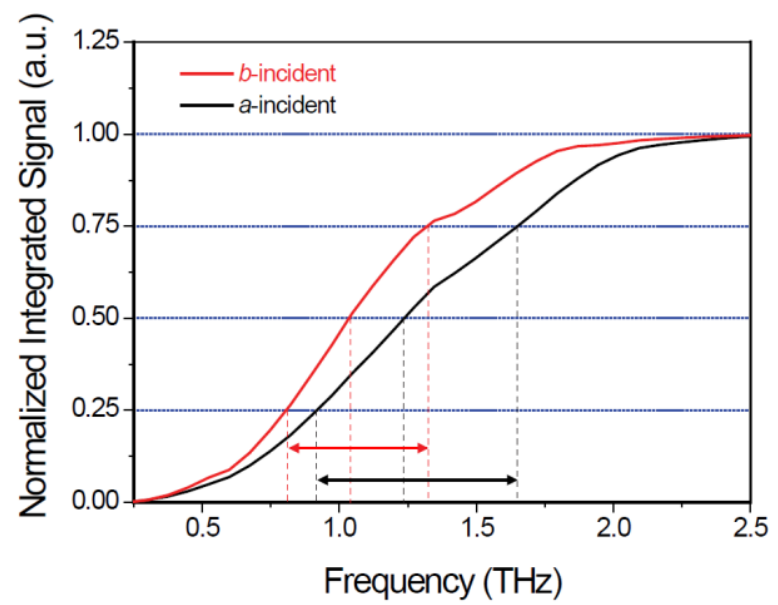

Figure S11. Normalized integrated $\mathrm{THz}$ amplitude as function of $\mathrm{THz}$ frequency, which is calculated from experimental frequency-domain amplitude spectra shown in Figure $2 b$. 


\section{References}

(R1) Kwon, S. J.; Jazbinsek, M.; Kwon, O. P.; Günter, P. Crystal Growth and Morphology Control of OH1 Organic Electrooptic Crystals. Cryst. Growth Des. 2010, 10, 1552-1558.

(R2) Kwon, O. P.; Kwon, S. J.; Jazbinsek, M.; Brunner, F. D. J.; Seo, J.-I.; Hunziker, C.; Schneider, A.; Yun, H.; Lee, Y.-S.; Günter, P. Organic Phenolic Configurationally Locked Polyene Single Crystals for Electro-optic and Terahertz Wave Applications. Adv. Funct. Mater. 2008, 18, 3242-3250.

(R3) Kwon, O. P.; Ruiz, B.; Choubey, A.; Mutter, L.; Schneider, A.; Jazbinsek, M.; Gramlich, V.; Günter, P. Organic Nonlinear Optical Crystals Based on Configurationally Locked Polyene for Melt Growth. Chem. Mater. 2006, 18, 4049-4054.

(R4) Spackman, M. A.; Jayatilaka, D. Hirshfeld Surface Analysis. CrystEngComm 2009, 11, 1932.

(R5) Spackman, M. A.; McKinnon, J. J. Fingerprinting Intermolecular Interactions in Molecular Crystals. CrystEngComm 2002, 4, 378-392.

(R6) McKinnon, J. J.; Jayatilaka, D.; Spackman, M. A. Towards Quantitative Analysis of Intermolecular Interactions with Hirshfeld Surfaces. Chem. Commun. 2007, 37, 3814-3816.

(R7) Lee, S.-H.; Kang, B.-J.; Kim, J.-S.; Yoo, B.-W.; Jeong, J.-H.; Lee, K.-H.; Jazbinsek, M.; Kim, J. W.; Yun, H.; Kim, J.; Lee, Y. S.; Rotermund, F.; Kwon, O. P. New Acentric Core Structure for Organic Electrooptic Crystals Optimal for Efficient Optical-to-THz Conversion. Adv. Opt. Mater. 2015, 3, 756-762. 